\title{
Образы визионеров и видений в «Церковной истории народа англов» Беды Достопочтенного
}

\author{
Никулина С.C. \\ Ивановский государственный университет, \\ Россия, 153025, Ивановская обл., г. Иваново, ул. Ермака, д. 39 \\ E-mail: sofya-golubeva@bk.ru
}

\begin{abstract}
Аннотация. Работа посвящена анализу способов классификации образов визионеров и образов, явленных им, в тексте «Церковной истории народа англов» Беды Достопочтенного. Рассмотрены причины, по которым тот или иной образ визионера появляется в тексте, а также почему именно такой тип визионера наделен конкретным образом, явленном в видении. Кроме того, прослеживается связь между образом видения, типом визионера и функциями конкретного эпизода, описывающего чудо визионерства. В соответствии с выделенными четырьмя основными функциями видений - познавательной, развлекательной, дидактической и прогностической создана классификация всех образов видений, описанных в «Церковной истории народа англов», определяющая доминирующий образ видения для конкретного визионера.
\end{abstract}

Ключевые слова: визионерская традиция, образы, Церковная история, классификация, Беда Достопочтенный.

Для цитирования: Никулина С.С. 2021. Образы визионеров и видений в «Церковной истории народа англов» Беды Достопочтенного. Via in tempore. История. Политология, 48 (2): 328-337. DOI: 10.52575/2687-0967-2021-48-2-328-337.

\section{Images of visionaries and visions in «Historia ecclesiastica gentis Anglorum» by Bede the Venerable}

\author{
Sofya S. Nikulina \\ Ivanovo State University, \\ 39 Ermak St., Ivanovo, Ivanovo region, 153025, Russia \\ E-mail: sofya-golubeva@bk.ru
}

\begin{abstract}
The article considers the classification of different types of visionaries and the images of their visions as exemplified in «Historia ecclesiastica gentis Anglorum», a fundamental work by Bede the Venerable written in the eighth century. Rich variety of types of visionaries creates the unique work where all the functions of visions - cognitive, entertaining, didactic and predictive - are represented to show the constant presence of God in everyday life. We have considered and shortly described all the episodes telling the reader about the miracle of visions, and we have proved that each type of visionary has its own range of images, and those images are connected with the target function of the episode. Taking into consideration all these factors we have created a new scheme, classifying types of visionaries and images according to their functions. According to this scheme, human images mostly perform all the four functions of visions, while the images of different objects and objectless images aim to represent only one or two functions, necessary in a definite episode.
\end{abstract}

Key words: visionary tradition, images, Historia ecclesiastica gentis Anglorum, classification, Bede the Venerable.

For citation: Nikulina S.S. 2021. Images of visionaries and visions in «Historia ecclesiastica gentis Anglorum» by Bede the Venerable. Via in tempore. History and political science, 48 (2): 328-337 (in Russian). DOI: 10.52575/2687-0967-2021-48-2-328-337. 


\section{Введение}

В агиографической литературе средневековья особое место уделено чудесам, творимым святыми, так как ни один праведник не мог считаться святым, если не был чудотворцем. Особое место среди всех чудес занимает явление визионерства, характерное для средневековой эпохи. Редкий исторический нарратив обходится без описания чуда визионерства, в том числе и «Церковная история народа англов».

\section{Результаты и их обсуждение}

Оригинальный текст работы не сохранился [Wallis, 2013], но известно, что этот монументальный труд был завершен к 731 году Бедой Достопочтенным, бенедиктинским монахом из Нортумбрии, одним из самых авторитетных и плодотворных Учителей Церкви [Holder, 1990; Ненарокова, 2003; Зверева, 2008]. Рассказывая историю христианства на территории древней Англии, Беда стремится показать «присутствие Бога в истории» [Orsbon, 2011, p. 24; Guiliano, 2015]; он убежден, что именно чудеса объединяют историю Англии со всем христианством [Rowley, 2003, p. 230]. Поэтому автор включает в повествование многочисленные упоминания видений, явленных и святым, и простым мирянам. Подобное разнообразие заставляет задать вопрос, какие персонажи получали те или иные видения и почему.

Это связано, по-видимому, с функциями видений, так как эти функции невозможно воплотить в равной степени, если рассказы о видениях будут слишком схожи. На основании анализа всех упоминаний чуда в «Церковной истории народа англов» мы выделили четыре функции рассказов о видениях: познавательную, развлекательную, дидактическую и прогностическую. Разумеется, это деление условно, а функции переплетаются между собой, но тем не менее возможно выделить одну наиболее яркую функцию конкретного видения.

К основной функции видений можно отнести в первую очередь дидактическую: рассказ визионера предостерегает слушателя об опасностях греховных искушений, дает силы вести образ жизни благочестивого христианина. Кроме того, более яркий след в сознании слушателя оставляли именно рассказы о мучениях, которые предстоят грешнику после смерти [Гуревич, 1981, с. 85], как, например, рассказ святого Фурсея о преисподней в главе 19-й второй книги и видение ада Дриктельмом в 12-й главе пятой книги. Дидактическая функция всего труда Беды становится еще более значимой в переводе латинского оригинала на древнеанглийский язык [McKinney, 2011, p. 122-123].

Другая функция видений - ознакомительная. Богословские тексты приоткрывали для читателя двери в тайну потустороннего мира, знакомя с его обитателями и уделом душ усопших в соответствии с их мирской жизнью. Рассказы визионеров были одним из немногих доступных источников знания об этом одном из самых важных вопросов, занимавших раннесредневекового христианина. И здесь многообразие образов визионеров гарантировало то, что слушатель, узнавая один и тот же сюжет из разных уст, отсеет все сомнения в его правдивости. Также слушатель мог найти такого визионера, чей образ жизни был бы близок его собственному, и будто примерить его рассказ на себя.

Третья основная функция видений - развлекательная, так как нередко подобные «занятные» рассказы вставлялись в текст с целью оживить повествование. И снова речь идет о вариативности - типов визионеров и образов, явленных им, которые приоткрывают потусторонний мир для слушателя и одновременно делают рассказ о загробном мире наглядным и запоминающимся.

Несмотря на то, что в отечественной литературе принято считать, что видение выполняло три вышеуказанные функции [Ярхо, 1989], будет уместным выделить четвертую функцию вставок о видениях - прогностическую. В таком аспекте задачей видения было указать визионеру о грядущих событиях, которые могли быть связаны и с реальным (Beda. HE II, 12) [Rowley, 2009, p. 166], и с потусторонним (Beda. HE V, 14) миром, или через визионера указать на такие события другим людям (Beda, HE IV, 25). Тонкая грань, отделяющая два мира, стирается, когда королю Эдвину, опечаленному своей участью, яв- 
ляется некто и утешает его. Странник не только предсказывает будущее короля, но и дает ему знак, еще раз встретив который, Эдвин поймет, какое решение будет верным. Вместе с прогностической функцией это видение ярко показывает и дидактический подтекст: увидев еще раз знак, показанный образом из видения, Эдвин пришел в христианскую веру. Интересен этот эпизод и тем, что он показывает, как потусторонний образ мог влиять не только непосредственно на визионера, но и на его окружение: странник обещает освободить Эдвина от всех напастей, убедив короля англов, настроенного против визионера, не причинять ему никакого зла (Beda. HE II, 12).

Во всем труде встречается только один рассказ, где видение пророчествовало бы о событиях реальной истории, и несколько эпизодов, в которых из видения герой узнал бы что-то о будущем, связанном с потусторонним миром. Как правило, такое пророчество говорит о скорой смерти визионера и показывает участь его души в загробном мире [Rowley 2009, p. 167]. Кроме этого, встречается и такой рассказ, где визионер узнает о скорой кончине другого человека (Beda. HE III, 8). Это представляется несколько нетипичным, но может объясняться тем, что и визионер, и женщина, о которой идет речь в видении, монахини, а значит, духовно близки друг другу (Иоанн 17: 20, 21). Эта связь между духовными сестрами-монахинями позволяет им передать важное послание даже между бренным миром и миром загробным.

Всего в труде Беды Достопочтенного насчитывается 14 эпизодов, где явлены видения. Некоторые из этих эпизодов лишь вскользь упоминают некий образ - чаще всего свечение, а некоторые представляют собой законченные рассказы, где визионер напрямую взаимодействует с представителями загробного мира. В зависимости от тональности видения образы, явленные визионеру, могли быть положительными, дарящими надежду свет, ангелы, души умерших близких (Beda. HE III, 19); или отрицательными, предостерегающими визионера и, соответственно, читателя (Beda. HE IV, 25).

На наш взгляд, классификация образов поможет более точно понять суть видения и его функции в тексте, так как уже существует ряд работ, посвященных классификации визионеров [Прогунова, 2015; Гвоздецкая, 2018б; Rowley, 2009], но еще не было проведено исследований образов, являющихся им. На наш взгляд, именно в образе и заключен весь концепт видения, именно через образ рассказ о видении выполняет свои функции.

Существует несколько оснований для различных классификаций. Проведя анализ всех образов в соответствии с критериями классификации, мы надеемся получить полные характеристики концептов видений и выяснить, как именно тот или иной образ функционирует в видении и почему именно такой сюжет Беда Достопочтенный выбрал для повествования в конкретной главе.

Самая яркая характеристика, отличающая сюжеты видений друг от друга, заключается в одушевленности образа видения. Можно выделить три категории таких образов: антропоморфные, предметные и беспредметные.

Конечно, именно антропоморфные образы делали рассказ о чуде наиболее захватывающим и запоминающимся, однако Беда не останавливается только на таком очевидном приеме и включает в текст «Церковной истории» также образы неодушевленные. С одной стороны, может показаться, что Беда играет на контрасте: антропоморфные образы встречаются именно там, где это наиболее важно, и чтобы читатель не воспринимал подобные видения как само собой разумеющееся, автор намеренно «приберегает» сложные образы для особых рассказов. Но только ли литературной цели служит подобное разграничение? Скорее всего, так как прежде художественной ценности Беда ставил ценность духовную, ответ можно найти, выяснив главную функцию видения, в котором появляется неодушевленный образ (Beda. HE IV, 7; Beda. HE IV, 25; Beda. HE V, 13).

Образы видений, в которых фигурирует предмет или какое-либо явление, встречаются в каждом эпизоде, где говорится о чуде визионерства. В первую очередь это относится к беспредметным образам, которые заключаются в трех концептах: звук, свет и за- 
пах. Эти концепты прослеживаются и в коротких, и в развернутых видениях. Ни один рассказ о чуде визионерства не обходится без упоминания неземного свечения. Образ особенного света подготавливает читателя к восприятию рассказа. Так, например, в 7-й главе четвертой книги Беда описывает, как монахини узрели на кладбище некий свет, который сошел с неба, чтобы указать им место их будущего упокоения (Beda. HE IV, 7). Помимо земного символа, этот свет указывает на то, что, несмотря на скорую кончину в ходе эпидемии чумы, монахини обретут Царство небесное, полное такого же света, затмевающего само солнце. В данном эпизоде беспредметный образ является центральной фигурой и выполняет дидактическую и прогностическую функции одновременно: указывая, как следует поступить, и даря надежду на лучшее будущее.

Что же касается концептов звука и запаха, то эти образы не встречаются отдельно от образов других категорий, являясь лишь дополнением к рассказу [Гвоздецкая, 2018а]. Соответственно, наиболее ярко эти концепты предстают в развернутых рассказах о потустороннем мире, где душа героя попадает за грань смерти: в видениях св. Фурсея (Beda. HE II, 19) и Дриктельма (Beda. HE V, 12). Видения имеют схожую структуру: визионер, сраженный неизвестным недугом, впадает в некое состояние, которое может называться «тонким сном», о котором стоит сказать отдельно.

Мотив «тонкого сна» - упоминание особого состояния, которым сопровождалось развернутое видение [Шилова, 2012]. Избранный Богом визионер засыпает, находясь между миром живых и мертвых, и так он способен видеть потусторонние образы или даже путешествовать по загробному миру. По распространенному убеждению, мотив «тонкого сна» является одним из устойчивых элементов при описании чуда визионерства [Прокофьев, 1964; Ярхо, 1989]. Тем не менее, например, мирянин Дриктельм (Beda. HE V, 12) не засыпает, а именно умирает, а затем воскресает [Esser-Miles, 2020, p. 3], что является отступлением от традиционной схемы. При наличии других устойчивых концептов, упомянутых в каждом видении, мотив тонкого сна присутствует не во всех эпизодах о загробном мире, описанных Бедой Достопочтенным. В видении же св. Фурсея мотив тонкого сна особенно важен, так как именно это состояние позволяет ему попасть в загробный мир.

В то время как близкие считают героя умершим и готовятся к его похоронам, его душа путешествует по загробному миру и видит преисподнюю, в которой томятся души грешников, и окраину Рая, где души обитают в вечном блаженстве. Закончив путешествие, душа возвращается в тело визионера, чтобы, пробудившись, он поведал о том, что был удостоен увидеть и тем самым направил неверных на путь истинный и еще больше укрепил в вере праведных. Описания звука и запахов создают в сознании читателя живую картину потустороннего мира, резко проводя черту между преисподней и Раем, в том числе вводя в текст антонимичные пары «благоухание» - «зловоние», «пение»- «крики», «тишина» - «грохот», «молитва» - «смех». В отличие от концепта света, который мог являться самостоятельным образом, концепты звука и запаха лишь дополняют образный ряд, составленный с помощью других приемов.

Эпизоды путешествий в загробный мир знакомят читателя со всем многообразием образов, причем явлены эти образы двум разным типам визионера: святому-праведнику и простому мирянину. Почему именно так? При кажущейся схожести структуры и содержания эти два эпизода все-таки многим отличаются. Прежде всего, видение Фурсея немного короче, однако показывает те аспекты загробного мира, которые были закрыты от Дриктельма. Это, на наш взгляд, объясняется тем, что Фурсей всю жизнь посвятил служению Богу и был несколько подготовлен к таинствам загробного мира. Огонь, который ранит душу Фурсея за незначительный проступок и оставляет на его теле ожог как знак воздаяния, опаляет душу праведного человека; Беда стремится убедить в том, что душа простого мирянина, пусть даже живущего по Христовым заповедям, могла полностью сгореть в пламени. Поэтому Фурсея спутники-ангелы проводят по самой геенне, а Дриктельм лишь проходит мимо и видит не четыре костра, как святой, а сплошной огонь вокруг. Тем не 
менее интересно и то, что Фурсея ангелы сопровождают на протяжении всего пути по преисподней, а спутник Дриктельма оставляет его на некоторое время одного, окруженного бесами, пугающими визионера. Безымянный спутник мирянина позднее объясняет, что уходил, чтобы узнать о судьбе Дриктельма, но тем не менее этот эпизод в сравнении с рассказом о Фурсее наводит на идею об аллегории: святой каждодневной молитвой окружил себя святостью, и ангелы всегда рядом с его душой [Harris, 2002, p. 273]. Мирянин, стараясь жить по слову Божьему, также получает провожатого, но как не может простой человек всегда и во всем безукоризненно выполнять Его заветы, так и его спутник оставляет его одного посреди хаоса, на который души сами себя обрекают. Эта сцена показывает контраст между спокойствием под защитой ангела при постоянной молитве и тем бессмысленным и жутким миром, в котором душа беззащитна, если не посвящает себя каждодневной молитве, отдаляясь от своего хранителя. Таким образом, есть весомые основания показать потусторонний мир и с точки зрения святого, и глазами простого мирянина.

Предметные образы чаще всего являются несамостоятельными, то есть не появляются сами по себе перед взором визионера, а сопутствуют образам из других категорий. Самым ярким подобным образом в тексте является книга. Интересно сравнить, как две противоположных по назначению книги показаны в видении грешника (Beda. HE V, 13). Умирая, герой видит, как в его дом входят два прекрасных юноши, в которых читатель узнает ангелов, и дают ему прочитать маленькую красивую книгу, в которой аккуратным почерком записаны добрые дела, которые умирающий когда-то совершил. После визионера окружают бесы и показывают ему большую книгу, страницы в которой покрыты корявыми записями. Бесы объясняют, что это записи всех злых и грешных деяний умирающего, и пугают его рассказами о горькой участи после смерти. Добрых дел слишком мало против прегрешений, и душа грешника обречена на страдания в преисподней. То есть книги, принесенные обитателями потустороннего мира, выполняют прогностическую функцию - предсказывают судьбу души умирающего - и вместе с тем дидактическую функцию, так как читатель, ассоциируя себя с героем рассказа, устрашится дня своей смерти и будет вести более благообразную жизнь.

Дидактическая функция достигает своего пика, перерастая в угрозу, в эпизоде, показывающем сам процесс отделения души от тела (Beda. HE V, 13). Беда описывает клинки, которыми бесы пронзают тело умирающего. Клинок - также несамостоятельный образ, символ невозвратности мирской жизни. Помимо прямого значения клинка как орудия умерщвления человека, образ острого предмета и боли от него может ассоциироваться с уколами совести, от которых грешник мучается, вспомнив все зло, которое он сотворил, и не имея больше возможности раскаяться в нем.

Видение безымянного грешника подробно и показывает разные образы, однако имеет существенное отличие от подобных видений святого и мирянина: визионер не попадает в состояние «тонкого сна», а действительно находится на грани смерти, его душе не дается шанса очиститься от греха и исправить посмертную судьбу. Подобная безысходность представляется не случайной: Беда намеренно вводит в текст такой тип визионера, чтобы, во-первых, усилить дидактическую функцию видения, показав читателю ужас последних минут мирской жизни; а во-вторых, оживить рассказ прениями у смертного одра, вызывая больший интерес у читателя.

Отдельно стоит эпизод, в котором грешник перед смертью видит место своих будущих мучений (Beda. HE V, 14): в преисподней, рядом с Сатаной и Каиафой, окруженный бушующим огнем. Беда ничего не говорит о состоянии героя в момент видения, но это и не важно, так как основной целью повествования является не рассказ о самом процессе получения тайного знания, как в других эпизодах, а краткое и яркое описание образа-картины, который, по сути, предметен, так как в нем нет действия, а герои застыли в своем мучении. Это единственный предметный образ, который явлен сам по себе и может считаться самостоятельным, своеобразным образом-сигналом. 
Наконец, интересны два образа, явленные женщинам во сне. Эрконготе, дочери кельтского короля Эрконберта, которая жила в монастыре и была очень благочестивой (Beda. HE II, 8), перед смертью было видение, в котором некие люди в белых одеждах вошли в монастырь, чтобы забрать «номисму из Кента». Основное значение здесь придается не пришедшим, а именно сравнению души визионера с золотой монетой, и, таким образом, сам визионер становится предметным образом своего же видения. Это видение также выполняет прогностическую функцию, так как Эрконгота понимает, что час ее смерти близок, оповещает об этом других монахинь и вскоре умирает.

Второй же рассказ о видении повествует о том, как некой женщине, Брегусвиде, приснился сон, в котором она не могла найти своего мужа (Beda. HE III, 23). Вместо него она обнаружила ожерелье, которое сияло ярчайшим светом. Ожерелье является образомсигналом, который олицетворяет ее дочь, Хильду. Хильда впоследствии стала первой женщиной в Нортумбрии, которая приняла монашеский обет и затем всецело посвящала себя управлению монастырем, аббатиссой которого она была.

Теперь, когда мы представляем функции и задачи неодушевленных образов в видениях, можно вернуться к антропоморфным образам. Несомненно ярко подобный образ предстает в уже упомянутом видении Эдвина, однако в «Церковной истории» есть еще несколько эпизодов со сложной структурой.

Одним из самых литературно красивых рассказов является история о Кэдмоне, монахе из обители Хильды (Beda. HE III, 24). В те времена был обычай на пирах по очереди исполнять песни, аккомпанируя себе на музыкальном инструменте, схожем с современной кельтской арфой. Кэдмон же этого дара был лишен от рождения и переживал из-за этого. Однажды во время такого пира монах в расстройстве пошел в хлев, так как пришла его очередь сторожить скот, и заснул там. Во сне к нему явился «некто в белых одеждах» и попросил спеть ему «о начале творения». Узнав о причине расстройства визионера, пришедший наделяет его даром стихосложения, прославившим монаха. То есть визионер выбран не только для того, чтобы наградить его тайным знанием, но и чтобы утешить его печаль. Эпизод показывает милость Бога к чистому сердцем христианину [Гвоздецкая, 2013] и выполняет дидактическую и развлекательную функции.

Как уже было сказано, Беда старался вложить истории о загробном мире в уста разнообразных типов визионеров. Так появляется эпизод, где видение показано ребенку (Beda. HE IV, 14). Ребенок, который остается в рассказе неназванным, жил в монастыре и обладал кротким нравом и крепкой верой. Видение является к нему в день его смерти, однако мальчик не находится в состоянии «тонкого сна», напротив, Беда особенно выделяет, что он второй день проводил в посте и молитве, хоть и был очень слаб. В видении мальчику явились апостолы Петр и Павел, которые рассказывают, что в тот же день заберут визионера на небо, но сначала предписывают ему принять Святое Причастие. Кроме того, они велят рассказать священнику, что эпидемия чумы, которая унесла много жизней, наконец закончится благодаря молитвам монахов и просьбе короля Освальда. Помимо основного содержания видения, мальчик с восторгом описывает невероятно прекрасную и величественную внешность апостолов, что призвано не только укрепить веру читателя, но и развлечь его рассказом о необычном виде святых. Выбор образа визионера представляется очевидным: чистый ребенок, прилежный в молитве и далекий от всего мирского, избран, чтобы лично увидеть двух апостолов - честь, которой даже святой Фурсей не был удостоен. Иного образа визионера в данном рассказе быть не могло.

Антропоморфный образ выполняет пророческую функцию, сообщив Адамнану скотту, жившему в постоянном посте и молитве, - о том, что скоро монастырь, в котором жили нечестивые монахини, сгорит дотла. Это видение (Beda. HE IV, 25) отличается тем, что читатель не «видит» образ видения напрямую через текст, а узнает о нем только со слов самого Адамнана. Несмотря на предостережения Божьего человека, монахини не меняют своего поведения, и пророчество исполняется, неся Божью кару. Образ визионера в 
этом рассказе - мирянин-аскет, который сначала ради искупления вины, а затем из любви к Богу ограничивает себя в еде и воде, всего себя посвящая молитве.

Наконец, несколько рассказов повествуют об образе умершего и описывают, как его душа попадает в Небесное Царство, охваченная светом. Особенно хорошо это показано в видении монахини Тортгиты (Beda. HE IV, 9), которая однажды увидела некий образ человека, облаченного в саван и поднимающегося в небо. Пророческая функция этого видения сразу исполняется: умирает настоятельница монастыря Эдильбурга, с которой Тортгита была очень близка [Прогунова, 2015]. Когда же приходит час кончины самой Тортгиты, она будто разговаривает с кем-то, кто предсказывает ее час кончины. Монахиня говорит, что к ней приходила Эдильбурга и возвестила о скором избавлении от земных мук, но образ видения не описан в тексте. Выбор именно монахини для представления подобного сюжета можно объяснить близкой душевной связью между монахинями, что более присуще женщинам.

Еще одним очевидным критерием является контраст «простой образ - составной образ». Если в отдельных рассказах видение лишь вскользь упомянуто как «свечение над неким местом» (Beda. HE IV, 7), то два особенно длинных и ярких рассказа о чуде визионерства включают в себя подробное описание загробного мира, явившегося героям (Beda. HE II, 19; Beda. HE V, 12). Соответственно, все описанные в тексте рассказа отдельные образы нужно рассматривать комплексно. В видениях же, где образ только слегка обозначен, он служит скорее для формального упоминания о факте видения, которое выполняет прогностическую функцию.

В «Церковной истории» видения являются разным типам визионеров, людям разных возрастов и сословий, имеющим разный жизненный опыт и взгляды на мир. Из всех типов визионера - король, благочестивый мирянин, мирянин-грешник, ребенок, святой, монах, монахиня - Беда особенно выделяет последний тип. Монахини являются визионерами в нескольких эпизодах «Церковной истории», и это единственный тип визионера, который упоминается неоднократно. Кроме того, монахини являлись и в качестве образов в видениях. Зрительные образы визионеров в соответствии с функциями и структурой видений можно представить в виде следующей схемы:

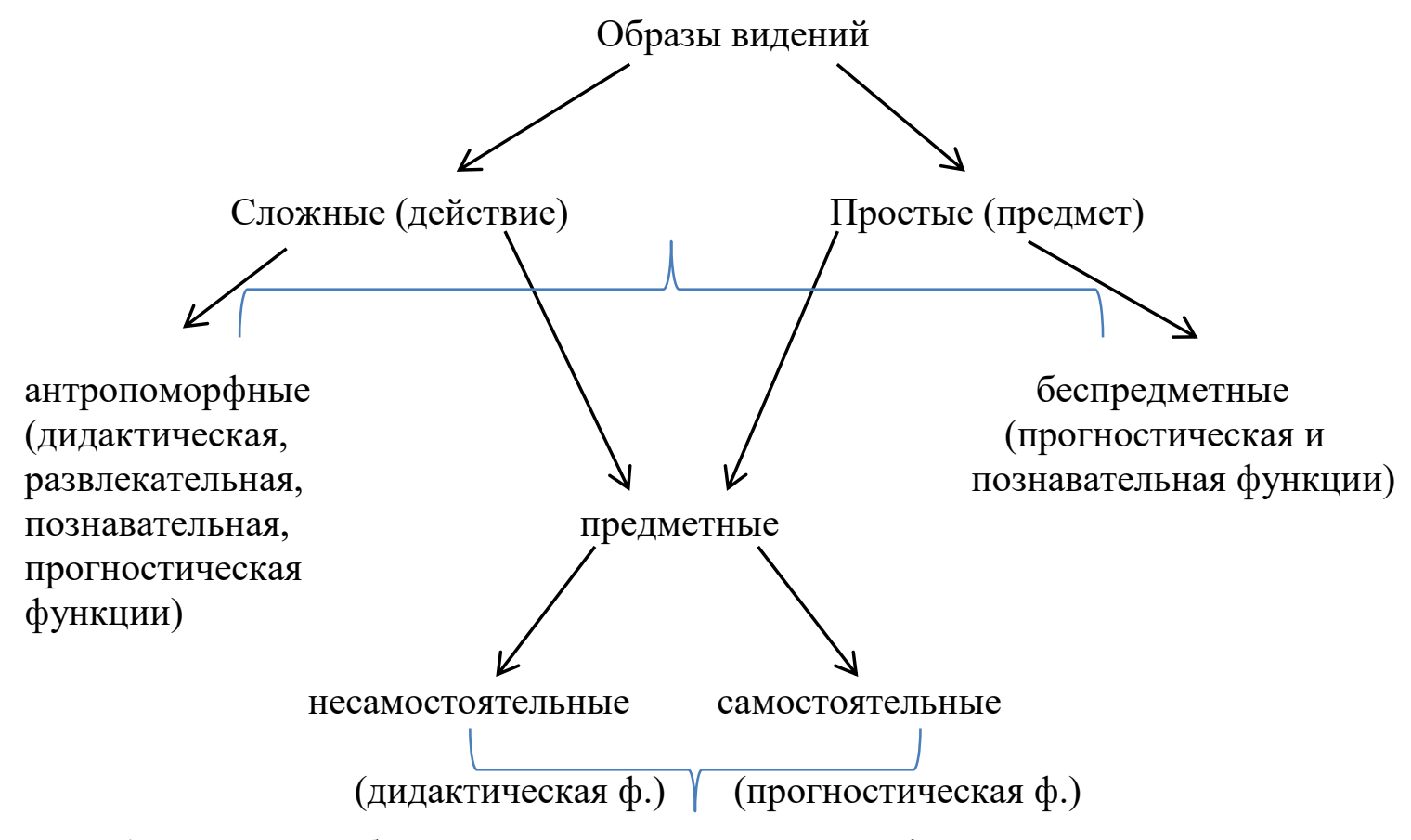

Рис. 1. Зрительные образы визионеров в соответствии с функциями и структурой видений

Fig. 1. Visual images of visionaries in accordance with the functions and structure of visions 
Как видно из схемы, видения, которые содержат антропоморфные образы, выполняют все четыре функции. Это объясняется тем, что во всех эпизодах, где фигурируют антропоморфные образы, присутствуют образы и предметные, и беспредметные, которые тоже выполняют ту или иную функцию, тем самым дополняя рассказ. Отдельные категории образов неотделимы от всей системы, как функции видения по большому счету неотделимы друг от друга. Тем не менее прослеживается связь между типом визионера и теми категориями образов, которые были ему явлены.

\section{Заключение}

На основании анализа типов визионера и явленных им образов можно утверждать, что Беда намеренно выбрал три самых ярких и предсказуемых типа визионера - святого, мирянина и грешника - для того, чтобы через их видения познакомить читателя с самыми значимыми аспектами загробного мира: таинством смерти, судом над душой и воздаянием за мирскую жизнь на том свете.

\section{Список литературы}

1. Гвоздецкая Н.Ю. 2013. Латинские наименования музыкально-поэтического творчества в древнеанглийском переводе «Церковной истории народа англов» Беды Достопочтенного. В кн.: Life beyond Dictionaries. Материалы юбилейной X Международной школы-семинара. Иваново, Ивановский государственный университет: 87-90.

2. Гвоздецкая Н.Ю. 2018а. Видения в «Церковной истории народа англов» Беды Досточтимого: скрытые смыслы. В кн.: Скрытые смыслы или грамматика нереального-2: материалы круглого стола (Москва, 14 декабря 2018). М., МГУ: 21-25.

3. Гвоздецкая Н.Ю. 2018б. Видения и визионеры в литературе раннесредневековой Англии и Исландии. Cursor mundi: человек античности, средневековья и возрождения, 10: 75-92.

4. Гуревич А.Я. 1981. Проблемы средневековой народной культуры. М., Искусство, 185.

5. Зверева В.В. 2008. «Новое солнце на Западе»: Беда Достопочтенный и его время. СПб., Алетейя, 48. PAH, 74.

6. Ненарокова М.Р. 2003. Досточтимый Беда - ритор, агиограф, проповедник. М., ИМЛИ

7. Прогунова Ю.М. 2015. Христианская и языческая традиция в «Церковной истории народа англов» Беды Достопочтенного (на примере «женской темы»). Вестник Нижегородского университета им. Н.И. Лобачевского, 3: 90-96.

8. Прокофьев Н.И. 1964. Видение как жанр в древнерусской литературе. Вопросы стиля художественной литературы. М., МГПИ им. В.И. Ленина: 35-36.

9. Шилова Н.Л. 2013. Мотив «тонкого сна» в литературных визионерских сюжетах. Ученые записки Петрозаводского Государственного Университета, 1 (130): 68-73.

10. Ярхо Б.И. 1989. Из книги «Средневековые латинские видения». Восток - Запад: Исследования, переводы, публикации, 4: 20.

11. Esser-Miles C.M. 2020. Heavenly Metaphors and the Transcendent Divine: Visions and light as methods to cross heavenly boundaries in Old English poetry. Available at: https://www.academia.edu/39460224 (accessed 7 September 2020).

12. Guiliano Z.M. 2015. The Allegorical Exegesis of Bede: 'Figures in History and the Shape of the Self'. Available at: https://www.academia.edu/1016410 (accessed 19 September 2020).

13. Harris S.J. 2002. Bede and Gregory's Allusive Angles. Criticism, 44 (3): 271-289.

14. Holder A.G. 1990. Bede and the Tradition of Patristic Exegesis. The Anglican theological review, 72 (4): 399-411.

15. McKinney W.A. 2011. Creating a gens Anglorum: Social and Ethnic Identity in AngloSaxon England through the Lens of Bede's Historia Ecclesiastica. PhD thesis. York, 122-123.

16. Orsbon D.A. 2011. Bede's Sacred Order: Schemes and Tropes in the Historia Ecclesiastica: Part I. The American Benedictine Review, 62 (1): 3-26 (126).

17. Rowley Sh. M. 2003. Reassessing Exegetical Interpretations of Bede's Historia Ecclesiastica Gentis Anglorum. Literature and Theology, 17 (3): 227-243 (230). 
18. Rowley Sh.M. 2009. The Role and Function of Otherworldly Visions in Bede's Historia ecclesiastica gentis Anglorum. In: The World of Travellers: Exploration and Imagination. Leuven, Peeters: $163-181$.

19. Saint Bede. 2011. Historia ecclesiastica gentis anglorum (Latin Edition). М., Нобель Пресc, 624.

20. Wallis Ch. 2013. The Old English Bede: Transmission and Textual History in Anglo-Saxon Manuscripts. PhD thesis. Sheffield, 17.

\section{References}

1. Gvozdetskaya N.Yu. 2013. Latinskie naimenovaniya muzykal'no-poeticheskogo tvorchestva v drevneanglijskom perevode «Cerkovnoj istorii naroda anglov» Bedy Dostopochtennogo [Latin names for musical and poetic creativity in the Old English translation of the «Ecclesiastical History of the People of the Angles» by Bede the Venerable]. In: Life beyond Dictionaries. Materialy jubilejnoj X Mezhdunarodnoj shkoly-seminara [Life beyond Dictionaries. Materials of the Jubilee X International School-Seminar]. Ivanovo, Ivanovo State University: 87-90 (in Russian).

2. Gvozdetskaya N.Yu. 2018a. Videniya v «Cerkovnoj istorii naroda anglov» Bedy Dostochtimogo: skrytye smysly [Visions in the «Ecclesiastical History of the People of the Angles» by Bede the Venerable: Hidden Meanings]. In: Skrytye smysly ili grammatika nereal'nogo-2: materialy kruglogo stola [Hidden Meanings or Grammar of the Unreal-2: materials of the round table] (Moscow, 14 December, 2018). Moscow, Publishing House of Moscow State University: 21-25 (in Russian).

3. Gvozdetskaya N.Yu. 2018b. Videniya i vizionery v literature rannesrednevekovoj Anglii i Islandii [Visions and Visionaries in the Literature of Early Medieval England and Iceland]. Cursor mundi: a person of antiquity, middle ages and renaissance, 10: 75-92 (in Russian).

4. Gurevich A.Ja. 1981. Problemy srednevekovoj narodnoj kul'tury [Problems of medieval folk culture]. Moscow, Iskusstvo, 185 (in Russian).

5. Zvereva V.V. 2008. «Novoe solnce na Zapade»: Beda Dostopochtennyj i ego vremja [«A New Sun in the West»: Bede the Venerable and his Time]. Saint-Petersburg, Aletejja, 48 (in Russian).

6. Nenarokova M.R. 2003. Dostochtimyj Beda - ritor, agiograf, propovednik [Bede the Venerable - rhetorician, hagiographer, preacher]. Moscow, Institute of World Literature of the Russian Academy of Sciences, 74 (in Russian).

7. Progunova Yu.M. 2015. Hristianskaya i yazycheskaya tradiciya v «Cerkovnoj istorii naroda anglov» Bedy Dostopochtennogo (na primere «zhenskoj temy») [Christian and pagan tradition in the «Ecclesiastical history of the People of the Angles» by Bede the Venerable (on the example of the «women's theme»)]. Bulletin of the Nizhny Novgorod University named after N.I. Lobachevsky, 3: 90-96 (in Russian).

8. Prokof'ev N.I. 1964. Videnie kak zhanr v drevnerusskoj literature [Vision as a genre in ancient Russian literature]. Questions of the style of fiction. Moscow, Moscow State Pedagogical Institute named after V.I. Lenin: 35-36 (in Russian).

9. Shilova N.L. 2013. Motiv «tonkogo sna» v literaturnyh vizionerskih syuzhetah [The motive of «delicate sleep» in literary visionary subjects]. Scientific notes of Petrozavodsk State University, 1 (130): 68-73 (in Russian).

10. Jarho B.I. 1989. Iz knigi «Srednevekovye latinskie videniya» [From the book «Medieval Latin Visions»]. East - West: Research, translations, publications, 4: 20 (in Russian).

11. Esser-Miles C.M. 2020. Heavenly Metaphors and the Transcendent Divine: Visions and light as methods to cross heavenly boundaries in Old English poetry. Available at: https://www.academia.edu/39460224 (accessed 7 September 2020).

12. Guiliano Z.M. 2015. The Allegorical Exegesis of Bede: 'Figures in History and the Shape of the Self'. Available at: https://www.academia.edu/1016410 (accessed 19 September 2020).

13. Harris S.J. 2002. Bede and Gregory's Allusive Angles. Criticism, 44 (3): 271-289.

14. Holder A.G. 1990. Bede and the Tradition of Patristic Exegesis. The Anglican theological review, 72 (4): 399-411.

15. McKinney W.A. 2011. Creating a gens Anglorum: Social and Ethnic Identity in AngloSaxon England through the Lens of Bede's Historia Ecclesiastica. PhD thesis. York, 122-123.

16. Orsbon D.A. 2011. Bede's Sacred Order: Schemes and Tropes in the Historia Ecclesiastica: Part I. The American Benedictine Review, 62 (1): 3-26 (126). 
17. Rowley Sh. M. 2003. Reassessing Exegetical Interpretations of Bede's Historia Ecclesiastica Gentis Anglorum. Literature and Theology, 17 (3): 227-243 (230).

18. Rowley Sh.M. 2009. The Role and Function of Otherworldly Visions in Bede's Historia ecclesiastica gentis Anglorum. In: The World of Travellers: Exploration and Imagination. Leuven, Peeters: $163-181$.

19. Saint Bede. 2011. Historia ecclesiastica gentis anglorum (Latin Edition). Moscow, Nobel Press, 624.

20. Wallis Ch. 2013. The Old English Bede: Transmission and Textual History in Anglo-Saxon Manuscripts. PhD thesis. Sheffield, 17.

\section{ИНФОРМАЦИЯ ОБ АВТОРЕ}

Никулина Софья Сергеевна, аспирант кафедры всеобщей истории и международных отношений Ивановского государственного университета, г. Иваново, Россия

\section{INFORMATION ABOUT THE AUTHOR}

Sofya S. Nikulina, post-graduate student of the Department of General History and International Relations, Ivanovo State University, Ivanovo, Russia 